\title{
Impasses históricos: Israel-Palestina na perspectiva de Le Monde Diplomatique
}

Juliana Sayuri Ogassawara

Universidade Federal de Santa Catarina - UFSC, Florianópolis, Santa Catarina, Brasil

\section{Resumo}

Este artigo analisa diferentes dimensões da cobertura de Le Monde Diplomatique ao conflito Israel-Palestina. Fundado na década de 1950, na França, como suplemento diplomático do diário Le Monde, o periódico paulatinamente reorientou o tratamento a Israel (inicialmente apresentado como um aliado próximo) e cristalizou-se como elemento-chave do movimento francês de solidariedade à Palestina. Este trabalho resgata tais reorientações editoriais e, posteriormente, discute a dimensão da memória do conflito a partir da edição de artigos antigos, escritos especialmente no contexto da Segunda Intifada (2000-2006) e reeditados para compor um dossiê de 2018, dedicado à Palestina.

\section{Palavras-chave}

Le Monde Diplomatique. Intelectuais. Islã. Política.

\section{Introdução}

Idealizado inicialmente como suplemento diplomático do diário Le Monde na década de 1950, Le Monde Diplomatique se tornou um prestigiado periódico de política internacional, paulatinamente marcando-se por uma linha editorial anti-imperialista e antineoliberal, o que inspirou a inauguração de diferentes edições internacionais sob o selo Diplomatique, estendendo-se da América Latina ao Oriente Médio.

Ímã de tensões internacionais, lar de 400 milhões de muçulmanos e somando séculos de história, o Oriente Médio despertou duelos intelectuais nas alas universitárias e na arena midiática, opôs perspectivas diametralmente distintas sobre o papel político do islã e suas representações, foi alvo de confrontos simbólicos, retóricos e bélicos. Lembremos da tese do orientalismo de Edward Said (2007), que reitera que o Oriente não é um fato inerte, mas uma ideia que carrega uma história e uma linha de pensamento, um imaginário e um léxico que lhe deram realidade diante do Ocidente. Segundo Said (2007), o orientalismo 
é um discurso lapidado a partir de relações assimétricas com o poder político (como um império), o poder intelectual (as ciências e ideologias dominantes de uma época) e o poder cultural (como as ortodoxias e tendências de textos). Logo, o Oriente é um fato cultural, intelectual e político.

Questões relacionadas ao Oriente Médio são pivôs de diversas discussões e clivagens políticas entre intelectuais e jornalistas de Le Monde Diplomatique (HARVEY, 2011; MEILHAC, 2006; WEIL, 2006). Tópicos como o papel do islã político, a presença islâmica na França, a proibição de símbolos religiosos (como o véu islâmico) nos colégios franceses, em 2004, e a publicação de caricaturas de Maomé no diário dinamarquês Jyllands-Posten, em 2005, posteriormente republicadas no semanário satírico francês Charlie Hebdo, opuseram duas alas políticas dentro de Le Monde Diplomatique: de um lado, intelectuais republicanos, que se afirmam laicistas, e às vezes abertamente anticlericais; de outro, os antigos comunistas, que são majoritariamente ateus, mas mais favoráveis à tolerância diante de uma perspectiva progressista da cultura muçulmana. Em fins de 2005 e princípios de 2006, o tom das disputas subiu a ponto de provocar as demissões simbólicas do redator-chefe Alain Gresh e do redator-chefe adjunto Dominique Vidal de suas funções hierárquicas, que continuaram na redação apenas como redatores.
Outros pontos provocaram divergências internas na redação, como a abertura ao filósofo franco-suíço e muçulmano Tariq Ramadan, o golpe militar na Argélia e o posicionamento diante do conflito Israel-Palestina.

Nestas páginas, discuto a perspectiva dos intelectuais franceses de Le Monde Diplomatique a propósito de Israel, da Palestina e do conflito que se tornou um dos principais impasses históricos do século XX ao presente século XXI.

No primeiro tópico, revisito as posições de Le Monde Diplomatique a respeito de Israel entre 1954 e 2005, partindo da investigação desenvolvida por Samuel Ghiles Meilhac. Na sequência, abordo o alinhamento de Le Monde Diplomatique à causa da Palestina durante a Segunda Intifada, entre 2000 e 2006, ancorada no estudo sociológico de Benjamin Weil. No terceiro tópico, por fim, analiso dimensões da memória do periódico acerca do conflito Israel-Palestina a partir do dossiê especial Palestine: un peuple, une colonisation, publicado por Le Monde Diplomatique entre fevereiro/março de 2018 , a fim de identificar continuidades e rupturas editoriais na cobertura do conflito histórico. Seguindo a tradição teórica de autores como Jean-François Sirinelli (1996), que posicionam periódicos e revistas como lócus privilegiado para a análise da história dos 
intelectuais, enquanto mediador de ideias nos debates culturais, ideológicos e políticos do tempo presente, considera-se Le Monde Diplomatique como observatório de primeira ordem para pensar o conflito árabe-israelense. Assim, pretende-se refletir sobre seus papéis enquanto observador, narrador e protagonista de uma história (LUCA, 2014), o que nos permite pensar relações entre jornalismo e história, a partir de uma chave de compreensão que arregimenta o texto (jornalístico) e o contexto (histórico) de sua produção, incluindo sua instrumentalização e possíveis apropriações (BARBOSA, 2007; BARBOSA, 2010; THOMPSON, 2009).

\section{Israel, de aliado diplomático a dominador}

Um território diminuto, encravado na costa oriental do Mediterrâneo, entregue pelos ingleses às jovens Nações Unidas, em 19471948, que ordenaram sua partilha em dois Estados independentes para dois diferentes povos. Esta é a arena da disputa que se descarrilou no século XX, marcando-o com tensões e confrontos.

Enquanto uma Palestina independente nunca se tornou realidade, Israel se expandiu, mas ficou atravessado por milhares de palestinos no caminho, cuja presença no decorrer dos anos reascendeu o dilema insolúvel entre Estado democrático e Estado judaico, com dois efeitos colaterais: de um lado, o surgimento de um fundamentalismo judaico; de outro, o armamento de um radicalismo árabe que se lançou para uma nova investida, a Guerra do Yom Kippur, de 1973. Como diz simbolicamente Peter Demant (2015), o Davi sionista se tornou um Golias imperialista, alfinetado pelas pedras de um Davi palestino.

Entre declarações diplomáticas, discussões políticas, negociações e tentativas de acordo, muitas pedras rolaram: a resistência palestina, que nas décadas de 1970 e 1980 foi principalmente secularista, fracassou diante da ideia propagada de que era preciso destruir Israel para se construir uma Palestina livre. O próprio processo de moderação provocou reações violentas, asfixiando as chances de conciliação. Foi neste contexto que a Organização para a Libertação da Palestina (OLP) fez fama com ações, entre militares e terroristas, e atentados vistosos, mas militarmente impotentes. Citando Demant (2010) mais uma vez, "politicamente, portanto, os palestinos conquistaram um lugar no mapa; militarmente, eles nunca ameaçaram Israel".

Ao investigar os posicionamentos de Le Monde Diplomatique a respeito de Israel entre 1954 e 2005, considerando ainda a diplomacia francesa frente ao Oriente Médio, o sociólogo Samuel Ghiles Meilhac diagnosticou 
transformações ao longo do tempo. Compreendendo Israel como um Estado-ator importante nas relações internacionais e peça essencial no tabuleiro do Oriente Médio, além de uma sociedade vinculada a um projeto político (o sionismo) e uma cultura, o autor aponta que, inicialmente, o jovem Estado de Israel, fundado em 1948, era tratado como um aliado no periódico francês, num momento em que as relações entre França e Israel estreitavam vínculos econômicos, diplomáticos, culturais e científicos.

Entre 1958 e 1967, os artigos de Le Monde Diplomatique, à época ainda um periódico voltado para as embaixadas, como dizia seu subtítulo Journal des Cercles Consulaires et Diplomatiques, foram marcados por uma visão positiva, muitas vezes incluindo artigos assinados por diplomatas israelenses - no vocabulário jornalístico, este estilo de publicação é conhecido como publi-reportagem, um gênero entre a publicidade e a reportagem. Em 1958, por exemplo, o magazine dedicou um dossiê de sete páginas ao país, feito pela própria diplomacia israelense, elogiando a performance do país na cultura, ciência, indústria, tecnologia e turismo. Nesse ínterim, Israel é representado a partir de diferentes ângulos, todos positivos: um aliado militar da França frente ao nacionalismo árabe, um produtor industrial forte, um destino privilegiado para o turismo religioso e arqueológico, uma cultura de profundos elos de fraternidade com os franceses e um símbolo vivo da renascença moderna da cultura judaica. Vale lembrar que poucos anos antes se desenrolaram acontecimentos importantes no território: a Guerra de Suez, de fins de 1956, em que os soldados israelenses, com apoio da França e do Reino Unido, ocuparam a Faixa de Gaza e a Península do Sinai integralmente. Para Meilhac (2006), publicar tal dossiê pro domo nesse contexto era, então, um sinal de solidariedade e apoio a Israel.

Depois de junho de 1967, mês marcado pela deflagração da Guerra dos Seis Dias contra Egito, Jordânia e Síria, Israel passou a ser visto com outros olhos dentro e fora das páginas de Le Monde Diplomatique. A posição francesa mudou diante do conflito, como se pode recordar a partir das declarações do general Charles de Gaulle, na memorável conferência de imprensa de novembro de 1967 que marcou o início do rompimento dos laços diplomáticos franco-israelenses tão firmes até então: nas palavras do presidente francês, os judeus correspondem a um povo "seguro de si e dominador", ao passo que Israel “organiza nos territórios que tomou a ocupação que não pode avançar sem opressão, repressão, expulsões; e que 
se manifesta contra ele uma resistência que, por sua vez, ele qualifica de terrorista". ${ }^{1}$

No início da década de 1970, Le Monde Diplomatique alterou sua orientação editorial sobre o país, a partir de duas rupturas. A primeira foi resultado de tais mudanças nas relações entre França e Israel que, embora tenham preservado elos culturais, diplomáticos e econômicos, perderam o caráter de aliança privilegiada - paulatinamente, passou-se a dedicar um olhar especial à questão palestina. A segunda resultou da própria transformação editorial de Le Monde Diplomatique sob a direção do jornalista francês Claude Julien, deixando de ser um simples suplemento diplomático e adquirindo os contornos engajados e a tradição terceiro-mundista que o marcam até o presente. Tal mudança se aprofundou na década de 1980, impulsionada por acontecimentos-chaves como a invasão israelense no Líbano (junho de 1982) e a Primeira Intifada (dezembro de 1987), subindo o tom com críticas às violações de direitos humanos por soldados israelenses na repressão à revolta palestina.

Foi nesta época que os jornalistas Alain Gresh e Dominique Vidal passaram a escrever para
Le Monde Diplomatique. Antigo militante do Partido Comunista Francês e filho biológico de Henri Curiel, fundador do movimento comunista egípcio, Gresh iniciou suas colaborações em 1983, foi integrado à redação em 1985, tornando-se redator-chefe em 1995. Também membro do Partido Comunista e filho do linguista belga Haïm Vidal Sephiha, um dos expoentes da cultura judaico-espanhola, Vidal atuou na revista comunista Révolutione passou a escrever no Diplô a partir de 1986, tornando-se redator-chefe adjunto em 1998. Juntos, Gresh e Vidal assinaram diversos livros sobre o Oriente Médio, como Les 100 clés du Proche-Orient (1986) e Palestine 47 (1987).

A centralidade das temáticas do Oriente Médio nas páginas do Monde Diplomatique está relacionada à influência intelectual exercida por Gresh e Vidal, considerados especialistas no conflito árabe-israelense (WEIL, 2006, p. 8) - na posição de jornalistas, incumbidos de escrever artigos próprios e também de editar artigos de diversos autores.

Ao assumir a direção a partir de 1990, o sociólogo espanhol Ignacio Ramonet imprimiu traços mais nítidos à linha editorial anti-imperialista e antineoliberal do magazine 
(SAYURI, 2018). Nessa década, destaca Meilhac (2006), foram publicados artigos originais abordando a pluralidade política e étnico-religiosa, questões identitárias e discussões intelectuais israelenses, permitindo ao leitor conhecer "um outro Israel", muito embora evidenciando raramente pontos positivos do país. Segundo o autor, diversos artigos posicionavam Israel como uma sociedade prestes a explodir, consumida por clivagens e graves desigualdades socioeconômicas, como se o único elemento de unidade nacional se sintetizasse no conflito com os árabes, especialmente os palestinos.

Os acordos de Oslo de 1993, entre o governo israelense, representado pelo primeiro-ministro Yitzhak Rabin, e a oLP, representada pelo líder Yasser Arafat, foram abordados na edição de novembro do magazine, a partir de um viés distante do otimismo midiático mundial pela configuração de "um novo Oriente Médio" a partir de mediações do governo norte-americano, representado pelo presidente Bill Clinton.

O dossiê, que se propõe a discutir as condições reais para a paz, contou com contribuições críticas de autores como Edward Said e Joseph Algazy. Said, que integrou o Conselho Nacional da OLP entre 1977 e 1991, considerava o acordo assinado a 13 de setembro de 1993, um simbólico fim à Primeira Intifada
(1987-1993), como "o ato de rendição dos palestinos, um tipo de Tratado de Versalhes", por privilegiar a segurança dominante de Israel e não endereçar nada aos palestinos vítimas das incursões israelenses. Neste texto, Said (1993) literalmente convoca os palestinos a abandonarem a atitude resignada e perseverarem na resistência enquanto direito inalienável de povos privados de soberania e independência.

Na edição de novembro de 1994, o autor palestino volta às páginas com críticas mais duras ao processo de paz, descrito como uma "mesquinharia" e "zombaria patética" aceita por "vítimas condescendentes" que apenas favorece a ocupação israelense. Na ótica de Said, Israel conseguiu convencer os dirigentes palestinos que só seria possível instaurar uma paz conforme suas condições (SAID, 1994). Na opinião de Meilhac, ao escolher publicar os escritos de Said, Le Monde Diplomatique deu voz a um palestino que critica frontalmente a política da OLP, denunciando seus erros no processo de paz (MEILHAC, 2006) - o que, na realidade, reverbera certas ideias do diretor, uma vez que, logo na edição seguinte, de dezembro de 1994, Ignacio Ramonet publica um editorial resgatando críticas aos acordos de Oslo, ironizando o "histórico" encontro entre Yasser Arafat e Itzhak Rabin para selar simbolicamente o fim do conflito e, inclusive, indicando a impotência da Autoridade 
Palestina para mudar o rumo da região (RAMONET, 1994).

Em agosto de 1998, outro editorial foi publicado por Ramonet questionando Israel a seus 50 anos, somando "formidáveis" conquistas em diversos campos (agricultura, ciência, tecnologia), sobre o destino de uma sociedade que se via dividida, desorientada e desequilibrada num mosaico multicultural. Na edição, Said publicou mais um artigo, uma resposta aos intelectuais árabes fascinados pelo filósofo francês Roger Garaudy que se convertera ao islamismo na década de 1980. Said assinala a importância de não segregar israelenses e palestinos, considerando estúpida a ideia de impor um boicote a tudo que é israelense (discussão que estava em voga na época num círculo de intelectuais progressistas árabes). O autor reafirma o que compreende como papel do intelectual enquanto uma responsabilidade de dizer a verdade o mais direta e sinceramente possível, o que implica não se preocupar nem em agradar nem em desagradar ao poder. Critica, a partir desta definição, duas trilhas que se bifurcavam: de um lado, endossos elogiosos aos acordos; de outro, a irresponsabilidade intelectual nas convocações de apelo nacionalista triunfalista, com ares antissemitas, incluindo a ideia absurda de que o holocausto seria apenas uma invenção sionista. O primeiro caso é ilustrado por intelectuais israelenses (da La paix maintenant) e egípcios (da Société du Caire pour la paix), ao endossarem sem restrições os acordos de Oslo. O segundo se refere às teses de Garaudy, autor de Les mythes fondateurs de la politique israélienne (1995), posteriormente condenado por negar crimes contra a humanidade. Said reafirma, assim, a necessidade de clareza e coragem intelectual para combater todo tipo de discriminação racial, não importa a sua fonte (SAID, 1998).

\section{Palestina, símbolo da resistência}

O sociólogo Benjamin Weil (2006) identifica a Palestina como o símbolo mobilizador por excelência no Monde Diplomatique, incorporando a ideia de resistência à opressão israelense, que é retratada como arquétipo do colonizador. Assim, seguindo a tradição terceiro-mundista da revista, os palestinos são representados como os novos "condenados da terra", para lembrar a expressão Les damnés de la terre de Frantz Fanon, o que traz uma pujança simbólica à demanda de causas mobilizadoras aos "órfãos" das revoluções, aglutinando diferentes linhas de esquerda que se fixam nas idealizações heroicas de resistência contra a globalização neoliberal.

Se no Monde Diplomatique a interpretação do conflito árabe-israelense parte de uma chave de leitura anticolonial, a Palestina seria um emblema da luta revolucionária e simbolizaria a causa universal a convocar o engajamento 
de seus intelectuais e jornalistas. $\mathrm{O}$ amplo apoio ocidental a Israel, lembra Peter Antes (2003), é visto como o último resíduo da tutela colonial, de tal sorte que as confrontações israelenses são compreendidas como parte de uma longa história de humilhações impostas aos árabes.

Ao tabular 174 artigos publicados por Le Monde Diplomatique referentes ao conflito durante a Intifada Al-Aqsa, entre 2000 e 2006, Weil identificou interessantes tendências de representação, que destaco a seguir: $88,5 \%$ dos artigos atribuem a responsabilidade pelo conflito árabe-israelense e/ou entraves atuais (fracasso nas negociações e violências diversas) unicamente a Israel; 6,9\%assinalam responsabilidade parcial aos árabes em certos aspectos do conflito, mas Israel é considerado o principal responsável; nenhum artigo considera os países árabes e/ou os palestinos como corresponsáveis pelo conflito. Na interpretação do sociólogo, a unilateralidade na responsabilização total ou quase-total a Israel indica o alinhamento ideológico de Le Monde Diplomatique à causa palestina, a partir de uma chave colonial na representação do conflito árabe-israelense a opor "opressor" e "oprimido" (WEIL, 2006).

Nesta linha, Ariel Sharon, que ocupou o posto de premiê entre 2001 e 2006, é tratado como "o general", ao passo que Yasser Arafat é "o resistente", referido como presidente da Autoridade Palestina ou simplesmente como "o presidente palestino". Posicionar os palestinos como "resistência" à opressão invoca a memória francesa vinculada positiva a essa expressão, da atitude heroica dos franceses resistentes que secretamente combateram os nazistas na Segunda Guerra Mundial. Impregnado de sentido histórico-político, o termo remete ainda à literatura terceiro-mundista das décadas de 1950 e 1970, o que permite sugerir ao leitor uma situação assimétrica de injustiça imposta aos palestinos, caracterizados como vítimas da opressão israelense e da indiferença internacional, em decorrência da "guerra israelense da informação", expressão do fotógrafo Joss Dray e do jornalista Denis Sieffert.

A respeito de tal desequilíbrio, Meilhac cita Gresh: "Nós somos frequentemente atacados e considerados como parti pris, ao mesmo tempo que nós defendemos esta solução [dois Estados para dois povos], nós nunca dispomos no mesmo patamar israelenses e palestinos. Não por uma diferença de natureza entre os dois povos, mas simplesmente pelo fato que nós sempre consideramos que há um ocupante e um ocupado, e não é a mesma coisa ser ocupante e ocupado. E então nós não podemos simplesmente dar o mesmo peso a dois protagonistas" (GRESH, 2005 apUd MEILHAC, 2006, p. 178). 
Entretanto, o posicionamento pró-Palestina, majoritário e às vezes a priori, traz implicações delicadas ao magazine, na linha tênue entre o posicionamento e o viés, na expressão francesa: prendre parti ou parti-pris? (MEILHAC, 2006). Citando novamente as estatísticas averiguadas por Weil, a ideia de que o Hezbollah e/ou o Hamas são organizações de "resistência" ou com papel positivo marcou $71,4 \%$ dos artigos publicados, ante a $28,6 \%$ que consideraram que as práticas dessas organizações não são aceitáveis. Embora muitos autores condenem atentados suicidas, não escondem brados triunfalistas do Hezbollah, o que reverbera ecos da fórmula "os fins justificam os meios" (WEIL, 2006, p. 50-52).

As declarações do primeiro-ministro francês Lionel Jospin de fevereiro de 2000 ilustram a disputa de narrativas na qual está imersa a escolha de expressões para se referir a tais organizações. Em visita oficial a Tel Aviv, Jospin classificou como "terroristas" as ações do Hezbollah no sul do Líbano, ocupado por Israel. O uso do termo deflagrou discussões polêmicas na França presidida por Jacques Chirac, além de reações violentas no Oriente Médio - Jospin foi inclusive hostilizado por estudantes palestinos na sua passagem pela Universidade de BirZeit, na Cisjordânia. O uso, afinal, de termos como "resistência" e "terrorismo" traz no bojo a discussão de diferentes acepções na história francesa: resistência tem um sentido positivo, de oposição legítima, que faz referência a La Résistance diante da ocupação nazista; terrorismo tem um sentido negativo, de violência ilegítima, que invoca a política jacobina do terror na Revolução Francesa (MEILHAC, 2006).

No entanto, uma ruptura marcou a cobertura de Le Monde Diplomatique sobre a Segunda Intifada, marcada pela disputa de influência entre Fatah e Hamas, atentados, bombas e bombardeios. Na edição de setembro de 2003, um artigo do jornalista britânico Graham Usher traz críticas duras e diretas aos radicais palestinos e seus ataques suicidas a civis israelenses, num contexto de ascensão de Mahmoud Abbas à Autoridade Palestina, contrastando com a visão benevolente do magazine ao levante palestino de outros tempos.

$\mathrm{Na}$ edição de maio de 2004 , sob a rubrica "vozes da resistência”, o filósofo francês Etienne Balibar argumenta a "universalidade" da causa palestina: o conflito pode não comportar uma demarcação absoluta (não é um confronto entre "bons" e "maus"), mas apresenta uma dissimetria flagrante que continua se acentuando: de um lado, uma potência militar, aliada dos norte-americanos; de outro, um povo que luta pela própria sobrevivência. Após lembrar a legitimidade da luta palestina, e a 
legalidade conferida pelo direito internacional e pelas resoluções das Nações Unidas, o autor indaga:

Essa negação da própria existência do povo palestino, da Naqba até o muro em construção, justifica todas as formas de resistência e principalmente o terrorismo ao qual recorrem, contra a população civil israelense, diferentes organizações, islâmicas ou não? É preciso se fazer essa pergunta, não só para 'responder' à argumentação de Israel e de seus defensores, mas por razões de fundo. E em termos não só morais, mas também políticos (BALIBAR, 2004, p. 26, tradução da autora). ${ }^{2}$

Nesta arena, o autor afirma que ações terroristas, perpetradas por uma parte palestina por desespero, impotência ou ideologia, islâmica ou não, favoreceriam apenas a estratégia israelense de destruição da sociedade palestina, pois lhe confere pretextos para elevar o nível de violência nas retaliações. Nesta crítica, uma das mais fortes aos palestinos durante a Segunda Intifada, o autor dedica diversas linhas a lembrar que a causa palestina é legítima, mas não justifica tudo.

Ainda na edição de maio de 2004, que marcou o 50 aniversário de Le Monde Diplomatique,
Ramonet dedicou o editorial para definir o que é resistência - o que pode ser lido como um manifesto da linha editorial pretendida pela maison francesa:

Resistir quer dizer não. Não ao desprezo. Não à arrogância. Não ao esmagamento econômico. Não aos novos maîtres $d u$ monde. Não aos poderes financeiros. Não ao G8. Não ao "consenso de Washington". Não ao mercado totalitário. Não ao mercado livre total. Não à dominação do "pôquer do mal" (Banco Mundial, FMI, OCDE, $\mathrm{OMC}$ ). Não ao hiperprodutivismo. Não aos organismos geneticamente modificados. Não às privatizações permanentes. Não à irresistível extensão do setor privado. Não à exclusão. Não ao sexismo. Não à regressão social. Não ao desmantelamento da seguridade social. Não à pobreza. Não às desigualdades. Não ao esquecimento do sul. Não à morte, todo dia, de 30.000 crianças pobres. Não à destruição do ambiente. Não à hegemonia militar de uma só superpotência. Não à guerra preventiva. Não às guerras de invasão. Não ao terrorismo. Não aos atentados contra as populações civis. Não aos racismos. Não ao antissemitismo. Não à islamofobia. Não à paranoia da segurança. Não à vigilância generalizada. Não ao policiamento das ideias. Não à degradação cultural. Não às novas censuras. Não às mídias que mentem. Não às mídias que nos manipulam. [...] Resistir é sonhar que um outro mundo é possível. E contribuir para

2 Cette négation de l'existence même du peuple palestinien, de la Nakba jusqu'au mur en construction, justifie-t-elle toutes les formes de résistance, et notamment le terrorisme au quel ont recours, contre la population civile israélienne, diferentes organisations, islamiques ou non? Il faut se poser cette question, pas seulement pour «répondre» à l'argumentation d'Israël et de ses défenseurs, mais pour des raisons de fond. Et en termes non seulement moraux, mais aussi politiques. 
construí-lo (RAMONET, 2004, p. 1, grifo nosso, tradução da autora). ${ }^{3}$

À época, Ramonet também posicionou uma crítica oficial à Intifada armada:

Nosso jornal nunca aceitou que, para defender os direitos que nós consideramos legítimos - a criação de um Estado Palestino como uma decisão das Nações Unidas -, era necessário utilizar meios ilegítimos, em particular, a violência terrorista em relação a inocentes e civis israelenses. Nós sempre condenamos os atentados contra as populações israelenses (RAMONET, 2004 apud MEILHAC, 2006, p. 158-159).

\section{Editar o passado}

Dedico as páginas seguintes a uma análise ancorada especialmente num documento de publicação mais recente: a edição especial intitulada Palestine: un peuple, une colonisation, que corresponde ao número 157 da revista bimestral Manière de Voir, veiculada entre fevereiro/março de 2018.

Além da dimensão do arquivo de Le Monde Diplomatique a respeito do conflito Israel
- Palestina, que totaliza mais de 500 documentos, a escolha se justifica a partir de duas premissas. A primeira se refere à proposta da edição especial Manière de Voir, revista de cerca de 100 páginas cuja primeira edição data de novembro de 1987, que pretende reunir os melhores e/ou mais importantes artigos do arquivo do magazine acerca de determinado tema dentro dos enjeux internacionais - um tipo de "enciclopédia contemporânea" ilustrada com infográficos, cartografias e cronologias. A segunda premissa se refere ao questionamento da memória que Le Monde Diplomatique pretende lançar sobre si mesmo, quiçá amenizando ou acentuando as divergências relatadas, o que nos permite indagar e situar historicamente suas continuidades e rupturas editoriais a respeito do conflito. Em outras palavras, no presente, que perspectiva lança Le Monde Diplomatique sobre suas próprias interpretações do impasse histórico?

Editado pelo jornalista argelino Akram Belkaïd e pelo jornalista francês Olivier

3 Résister, c'est dire non. Non au mépris. Non à l'arrogance. Non au broyage économique. Non aux nouveaux maîtres du monde. Non aux pouvoirs financiers. Non au G8. Non au «consensus de Washington». Non au marché totalitaire. Non au libre-échange intégral. Non à la domination du «poker du Mal» (Banque mondiale, FMI, OCDE, OMC). Non à l'hyperproductivisme. Non aux organismes génétiquemen tmodifiés. Non aux privatisations permanentes. Non à l'irrésistible extension du secteur privé. Non à l'exclusion. Non au sexisme. Non à la regression sociale. Non au démantèlement de la Sécurité sociale. Non à la pauvreté. Non aux inégalités. Non à l'oubli du Sud. Non à la mort, chaque jour, de 30000 enfants pauvres. Non à la destruction de l'environnement. Non à l'hégémonie militaire d'une seule hyperpuissance. Non à la guerre préventive. Non aux guerres d'invasion. Non au terrorisme. Non aux attentats contre les populations civiles. Non aux racismes. Non à l'antisémitisme. Non à l'islamophobie. Non au tout-sécuritaire. Non à la surveillance généralisée. Non au flicage de la pensée. Non à l'abaissemen tculturel. Non aux nouvelles censures. Non aux médias qui mentent. Non aux médias qui nous manipulent. [...]Résister, c'est rêver qu'un autre monde est possible. Et contribuer à le bâtir. 
Pironet, o dossiê especial Palestine: un peuple, une colonisation é composto por 25 artigos (incluindo três inéditos e dois muito antigos, datados de 1960 e 1969), assinados por autores como Alain Gresh, Dominique Vidal, Graham Usher, Gilbert Achcar, Gérard Chaliand, Éric Rouleau e Edward Said.

Gresh escreveu na edição de junho de 2017 a respeito dos 50 anos da Guerra dos Seis Dias - e este foi um dos escritos escolhidos para compor o dossiê de 2018. O autor insere o movimento de resistência palestina num contexto internacional marcado pela luta dos povos da Indochina contra a intervenção norte-americana, pelas guerrilhas latino-americanas e pela ascensão de movimentos armados contra o apartheid sul-africano. $O$ autor assinala que, no século XX, duas causas foram capazes de promover mobilizações que ultrapassaram as fronteiras nacionais: o Vietnã e a África do Sul. Pondera que o número de mortos não foi o principal motivo para a indignação internacional, mas o sentido simbólico das situações. Assim, ao argumentar que um conflito pode transbordar os limites geográficos para adquirir um significado "universal" a expressar "a verdade de uma época", o autor inclui a Palestina como uma causa similar ao Vietnã e à África do Sul, com dimensão simbólica e universal. "Com a Palestina, o conflito mais longo da época contemporânea, ultrapassamos a disputa puramente territorial. Mais que uma questão de solo, trata-se de uma questão de justiça, ou melhor, de injustiça, que se reinicia sem cessar" (GRESH, 2018, p. 97). Gresh indubitavelmente maximiza a dimensão do movimento de solidariedade à questão palestina ao afirmar que, no mundo todo, milhões foram capazes de se projetar na luta palestina, que remete à sua própria revolta. No palestino, diz o autor, pode projetar-se "o jovem dos bairros relegados do Ocidente, o indiano expulso de suas terras, o irlandês orgulhoso de seu passado de luta contra o colonialismo britânico" (GRESH, 2018, p 97, tradução da autora). ${ }^{4}$ Quanto desta afirmação advém de um wishful thinking retórico, de uma idealização da resistência palestina, conforme indicou o estudo de Benjamin

4. Avec la Palestine, le conflit le plus long de l'époque contemporaine, nous dépassons le différend purement territorial. Plus qu'une question de sol, c'est avant tout une question de justice, ou plutôt d'injustice sans cesse recommencée. [..]) À travers le monde, des millions de personnes ont pu se projeter dans le combat que mènent les Palestiniens. II renvoie à leur propre révolte contre les discriminations et pour l'égalité des droits. À la figure du Palestinien peuvent s'identifier le jeune des quartiers relégués de l'Occident, I'Indien expulsé de ses terres ou l'Irlandais fier de son combat passé contre le colonialisme britannique. Même si elle est loin de garantir un triomphe dans leur combat, cette solidarité reste l'un des atouts majeurs des Palestiniens et une garantie, au-delà de leur propre détermination, que leur cause demeurera vivante. 
Weil, ou de uma identificação de fato de atores mobilizados mundo afora em prol da Palestina atualmente?

No dossiê de 2018, é significativo o resgate de um artigo de 1969, do escritor francês Gérard Chaliand, autor de Mitos revolucionários do Terceiro Mundo, sobre a resistência palestina. Lembra Chaliand que, após a Guerra dos Seis Dias, três organizações palestinas trilharam caminhos diferentes: a olP, o Fatah e os Héros du retour - AbtalAl-Aouda, um dos núcleos, ao lado do setor palestino do Movimento Nacionalista Árabe (MNA), da futura Frente Popular de Liberação da Palestina (FPLP). Enquanto a OLP é considerada por outras organizações palestinas como um ministério paralelo de relações internacionais, marcada por corrupção e nepotismo, o Fatah é tido como o primeiro movimento propriamente palestino depois da diáspora de 1948. Nas páginas presentes, Chaliand elenca as diretrizes do Fatah: a violência revolucionária é a única via para a libertação da pátria; tal violência deve ser exercida pelas massas populares; tal violência revolucionária visa liquidar a identidade sionista no território palestino, sob suas formas militares, política e econômica; a ação revolucionária deve ser independente e de longa duração (CHALIAND, 2018). Para um dossiê publicado a 2018, não é de se questionar a ausência de ponderações sobre os rumos tomados pela resistência armada ao reeditar um artigo antigo? Seria anacronismo? Ou mero revisionismo reavaliar as experiências da resistência armada? Embora marque presença um box com considerações do intelectual libanês Samir Frangié sobre a luta armada na década de 1970, afirma este, entretanto, que a inabilidade dos países árabes para possibilitar a liberação palestina impôs ao povo palestino a necessidade de adotar organismos de combate independentes, e que, para "liberar as energias palestinas e árabes bloqueadas por essa crise da resistência que o recurso ao terrorismo se impôs aos militantes do setembro negro como um maneira de romper, na prática, as barreiras ideológicas e políticas a uma verdadeira tomada de consciência revolucionária” (FRANGIÉ, 2018, p. 19, tradução da autora)?5

No dossiê foram reeditados os já citados artigos críticos de Graham Usher (2003) e de Edward Said (1993). Said critica que a celebração midiática dos acordos de Oslo, o ritual de reconciliação entre Arafat e Rabin na sua expressão, eclipsou a realidade, "um ato de 
rendição do povo palestino, um tipo de Tratado de Versalhes" (SAID, 1993, p. 4). Para Said, muitos dirigentes e intelectuais palestinos insistiram em considerar o acordo como "uma vitória" - expressão escolhida também pelo escritor israelense $\mathrm{Amos} \mathrm{Oz}$, mas considerando os acordos como uma conquista histórica do sionismo. O autor critica a resignação da OLP ao assinar o acordo, visto que Israel continuava ocupando Cisjordânia e Gaza - e que, no documento, o ponto principal é garantir a segurança de Israel; a segurança da Palestina diante das incursões israelenses não é sequer citada. Neste contexto, Said enfatiza que a Intifada, a de 1987 a 1993, não encarna a violência ou o terrorismo, mas o direito de resistir.

À ideia da Primeira Intifada como resistência, tal qual pontuara Said, Gresh traz um olhar otimista à Segunda Intifada, que se desenrolou após a visita de Sharon à esplanada das mesquitas de setembro de 2000 . Neste artigo, o autor considera que a explosão ilustra a exasperação dos palestinos diante de um processo de paz parado, da divisão de seus territórios e da degradação de suas condições de vida. Para Gresh, a mensagem dos insurgentes é clara: Israel deve escolher entre a paz e as colônias, colônias que os estatutos do Tribunal Penal Internacional, adotados em julho de 1998, qualificam como "crime de guerra" (GRESH, 2018, p. 32). Diz o autor que, assim como a revolta anterior, esta seria espontânea e popular, aglutinando Fatah, Hamas e Jihad Islâmica, além de outras organizações saídas da Primeira Intifada, reconhecendo a preponderância do Fatah. A ótica do autor trazia expectativas revolucionárias sobre a Segunda Intifada de 2000 , para "renovar as regras do jogo para levar a uma paz justa" com a fundação de um Estado palestino com Jerusalém Oriental como capital, ao lado de um Estado israelense com Jerusalém Ocidental como capital e, para tanto, "a utilização da violência, inclusive armada, contra a presença israelense nos territórios ocupados - soldados e colonos - representa a originalidade desse movimento" (GRESH, 2018, p. 33, tradução da autora). ${ }^{6}$

Críticas incisivas sobre a resistência palestina na Segunda Intifada se encontrariam

6 "Ces inacceptables injonctions, mais aussi la victoire du Hezbollah au Liban sud, avec le retrait israélien de mai 2000, grâce à la lutte armée, ont été les ingrédients du déclenchement du soulèvement palestinien. Son objectif? Rénover les règles du jeu pour aboutir à une paix juste fondée sur la coexistence de deux États. [...] L'encadrent, pour l'essentiel, le Fatah, l'organisation de Yasser Arafat, qui avait été relativement marginalisée par l'Autorité palestinienne, et les cadres moyens issus de la première Intifada. Toutes les organisations nationales et islamiques, y compris le Hamas et le Djihad islamique, sont regroupées au sein d'une direction commune - ce qui ne s'était pas produit en 1987 - et reconnaissent la prépondérance du Fatah. L'utilisation de la violence, y compris armée, contre la présence israélienne dans les territoires occupés - soldats et colons - représente l'originalité de ce mouvement." 
especialmente a partir do referido artigo de Graham Usher. Há, porém, sensíveis diferenças diante da versão original. Na edição realizada para o dossiê de 2018, o destaque (linha fina, no jargão jornalístico) busca sintetizar as ideias do autor como:

Para os palestinos, viver sob a dominação israelense é sinônimo de combate para defender seus direitos. É também uma experiência que atiça rivalidades e divisões políticas, sobretudo quando a violência, talvez fratricida, se assume. Porta-voz oficial das aspirações de seu povo, a Autoridade Palestina está fadada a uma lacuna constante entre condenação da ocupação e política conciliatória, especialmente sobre questões de segurança (USHER, 2018, p. 43, grifo nosso).

Na versão original de 2003, entretanto, o destaque é outro:

Israel, como o Hamas, rejeitou o cessar-fogo proposto no dia 23 de agosto pela Autoridade Palestina. Com seus atentados cegos, as organizações islamistas têm uma pesada responsabilidade na escalada. Mas o governo israelense fez tudo para sabotar o roadmap: recusa de se retirar da Cisjordânia, construção do muro, assassinato de dirigentes palestinos. Três anos após o início da Intifada, a resistência palestina está diante de um verdadeiro impasse (USHER, 2003, p. 12, grifo nosso).
O autor ali sinaliza que a militarização da Segunda Intifada levou a um impasse para os palestinos: de um lado, a condenação das ocupações israelenses; de outro, as políticas de conciliação - um impasse que persiste até os dias atuais no Monde Diplomatique.

Para Usher, o destino da Intifada teria sido selado num domingo de março de 2002, com o assassinato de 105 israelenses num hotel de Netanya, o que levaria Sharon a levantar a "guerra contra o terrorismo" e esmagar a AP, Arafat e Oslo. Note-se que, na versão original do artigo, tal crime foi caracterizado pelo autor como "atrocidade final" (l' ultime atrocité), enquanto a edição do dossiê substituiu a expressão por "atentado terrível" (terrible attentat). Além da substituição das palavras, outras considerações foram suprimidas da versão original. Sobre o destino da Intifada, por exemplo, no dossiê foi riscado o trecho que dizia:

Essa derrota era previsível para uma revolta sem objetivos e sem estratégia, se não uma vaga consciência nacionalista que as disposições dos acordos de Oslo deveriam ser revisadas e corrigidas a todo custo, o que implicava a substituição dos dirigentes que as negociavam (USHER, 2003, p. 12, tradução da autora). ${ }^{7}$ 
Outros 14 parágrafos do artigo original foram apagados, incluindo uma longa discussão sobre as alternativas possíveis de liderança: a AP, com diferentes vertentes, mas de acordo para se resignar ao road map traçado pelo jogo das relações internacionais e para renunciar ao "terrorismo"; o Tanzim, facção militar do Fatah, compelido, segundo o autor, a questionar a justiça da Intifada armada como estratégia de liberação; e a "resistência" armada, da ala radical do Hamas e de dissidentes do Fatah como a Brigada dos Mártires de Al-Aqsa e os comitês de resistência popular, embalada por uma ideologia islamista potente, que implicitamente compreendia que só seria possível forjar um novo movimento nacional sobre os escombros do movimento nacional anterior. Na versão atualizada do artigo, não há nenhuma menção ao Hamas, apenas ao Tanzim, braço-armado do Fatah. As aspas na palavra "resistência" foram postas por Usher no artigo original - e Meilhac tem razão ao destacar que a escolha do sinal gráfico é reveladora: quer dizer que, diante de atentados "atrozes" com consequências "catastróficas" para os palestinos, expressões do autor na versão original, as aspas para "resistência" põem em dúvida a precisão da palavra para se referir aos responsáveis por tais agressões (MEILHAC, 2006, p. 157).

O timing, porém, é interessante. A temporalidade importa, afinal, para o jornalismo e para a história. A história faz-se a partir do tempo: um tempo complexo e construído, que não é o fluir dos relógios, mas o incorporar das questões da época, dos documentos e dos acontecimentos (PROST, 2017). E o tempo não para: é evidente que o presente não é, nem poderia ser, simples "cópia-carbono" do passado (HоBSBAWM, 1998, p. 38).

O tempo presente, enquanto transição instável e incerta, leva a novas reflexões sobre a história, que implica a busca de novas chaves de leitura para pensar as passagens entre o passado e o futuro (ROUSSO, 2016). É o que teoriza o historiador alemão Reinhart Koselleck ao propor as noções de espaço de experiência e horizonte de expectativas.

A experiência pertence ao passado que se concretiza no presente, através da memória e dos vestígios das fontes históricas. A experiência, diz Koselleck, é o passado atual, no qual acontecimentos foram incorporados e podem ser lembrados. Já a expectativa, que mira o futuro, corresponde a um universo de antecipações do amanhã, crivando o presente de angústia, desejos, esperanças, inquietudes e temores. Nas tensões entre espaço de experiência e horizonte de expectativa se tece o tempo histórico. Os acontecimentos aconteceram de uma vez por todas, mas as experiências ancoradas neles podem mudar com o correr do tempo, superpondo-se, impregnando-se, 
alavancando novas esperanças ou desilusões, abrindo brechas para novas expectativas (KOSELLECK, 2006).

O tempo é um espelho que nos distorce, como lembra o historiador britânico Tony Judt, ao revirar o passado imperfeito dos intelectuais franceses fascinados pelo comunismo soviético no pós-guerra, a ponto de negar as evidências dos gulags e outros disparates stalinistas (JUDT, 2007). Cristalizar no presente um olhar sobre o passado palestino e suas inquietações para o futuro também tem suas implicações aos intelectuais franceses do Monde Diplomatique.

Enquanto Meilhac sinalizou rupturas na abordagem a Israel entre 1954 e 2005, Weil assinalou ângulos diferentes a Israel e Palestina entre 2000 e 2006, época marcada pela irrupção da Segunda Intifada e pelo auge das discussões entre os intelectuais franceses do Monde Diplomatique a respeito do islã político. A 2018, porém, ao realizar uma edição especial (Manière de Voir) dedicada à Palestina, Le Monde Diplomatique traz ao leitor artigos diversos sobre acontecimentos que marcaram época: o fracasso do processo de paz, o fervilhar da resistência, a dimensão internacional do conflito.

Mas editar é escolher. Editar um dossiê tem certo caráter de "palavra final" almejada pelas posições do magazine a respeito de determinado assunto, um tipo de documento que se pretende senão atemporal, que traga atualizações e resista ao tempo. É um processo ativo que abarca ações sobre o que manter, o que dispensar e o que acrescentar, o que levanta todo um quadro de referências sobre o que é importante ao momento presente. Implica, assim, uma escolha sobre sua própria memória, o que se quer lembrar, o que se prefere esquecer, as ressalvas que se consideram importantes, as relativizações que se passam dispensáveis. A memória, se é preciso lembrar, é talhada por operações ideológicas e processos psicossociais de representações de si próprio, reestruturando as arestas de um universo simbólico (MENEZES, 1992).

Se o mundo pode ser lido como uma "babélica narrativa”, uma narrativa que taquigrafa, traduz, sublima, filtra e fabula (IANNI, 2000), é interessante pensar as narrativas jornalísticas para além do viés simplista de manipulação midiática, inserindo a produção jornalística na dimensão declaratória da memória que produz uma linha de continuidade do presente com o passado (BARBOSA, 2017).

O perfil editorial de Le Monde Diplomatique, composto por artigos e ensaios extensos de escritores e editores especializados, escoltados por glossários, notas e referências bibliográficas, se propõe a ultrapassar a efemeridade das narrativas jornalísticas usuais, 
privilegiando a análise. A proposta de Le Monde Diplomatique é oferecer uma abordagem sobre questões-chaves da contemporaneidade a partir de uma perspectiva diferente da mídia mainstream, uma manière de voir singular. Busca inserir-se, portanto, entre a (relativa) transcendência dos livros e a (relativa) transitoriedade dos jornais diários. Faz-se, assim, tal qual uma revista, ocupando-se do presente, mas dialogando com o passado e o futuro.

Para Le Monde Diplomatique, o futuro deveria levar à libertação da Palestina, mediante a instauração de dois Estados independentes. O passado, por sua vez, é descrito no dossiê recente de Manière de Voir como um histórico de luta legítima e resistência da Palestina diante de uma disputa de forças assimétricas travada com Israel, mas mitigando ou obliterando diversos detalhes importantes de tal histórico, como mostra a surpreendente supressão de trechos inteiros e expressões no artigo crítico de Graham Usher, cujo teor original poderia ser sintetizado no aforismo: "os fins não justificam os meios" - uma ideia literalmente apagada neste resgate de memória dos arquivos do Diplô. A ausência pode supor silêncio, supressão, esquecimento ou outros motivos, mas o fato é que a ausência se faz presente. E o presente é prenhe de conflitos.

Autor de diversos livros sobre jornalismo e vários editoriais sobre os princípios de Le Monde Diplomatique, Ignacio Ramonet assim descreveu a proposta do periódico no editorial de janeiro de 2005 :

Nós queremos ser o jornal da sociedade em movimento, dos que querem que 0 mundo mude. E estamos dispostos a nos mantermos fiéis a princípios fundamentais que caracterizam nossa maneira de informar. Moderando a aceleração midiática; apostando num jornalismo das luzes para dissipar as sombras da atualidade; interessando-nos por situações que não estão sob os refletores da atualidade, mas que ajudam a compreender melhor o contexto internacional; propondo dossiês cada vez mais completos, mais profundos e melhor documentados sobre os grandes temas contemporâneos; indo ao fundo dos problemas, com método, rigor e seriedade; apresentando informações e análises inéditas que muitas vezes permaneciam ocultos e atrevendo-nos a ir na contracorrente das mídias dominantes. Estamos convencidos de que a qualidade da informação depende do debate cívico. A índole desse debate determina em última instância a riqueza da democracia (RAMONET, 2005, p. 1, tradução da autora). ${ }^{8}$ 
Assim, Le Monde Diplomatique reivindica para si e para sua memória uma perspectiva alternativa sobre o mundo, distinta da mídia mainstream - esta, a seu ver, uma indústria da informação, feita de conglomerados midiáticos comprometidos com interesses econômicos e políticos, fadada a publicar especulações e espetáculos. Entretanto, na construção dessa memória, um campo de contradições e disputas, entrincheira-se mais uma vez ao lado da resistência palestina independentemente de seus desdobramentos armados.

\section{Considerações finais}

De um periódico inicialmente destinado a diplomatas na década de 1950 (à época, seu subtítulo era Journal des Cercles Consulaires et Diplomatiques) a um magazine de tradições terceiro-mundistas desde a década de 1970 até o presente (atualmente, seu slogan é Mensuel critique d'informations et d'analyses), Le Monde Diplomatique se situa no cruzamento entre a universidade, o jornalismo e o ativismo, engajado e envolvido nas discussões do tempo presente. Firmou-se como elemento-chave do movimento francês de solidariedade à Palestina (MEILHAC, 2006).
Datado de 2018, o dossiê analisado pertence ao muito contemporâneo, embora revisite artigos antigos (de 1960 a 2017). Foi editado tempos após as aposentadorias de Alain Gresh (em 2016), Dominique Vidal (2010) e Ignacio Ramonet (2008), afastando-se do bureau francês, indicando a continuidade de uma inclinação editorial que tende a minimizar a responsabilidade palestina por agressões e atentados, considerando-os como apenas reações à política imperialista israelense.

A inserção de movimentos armados na resistência no conflito Israel-Palestina ilustra um dilema maior dos intelectuais do Monde Diplomatique sobre suas posições imprecisas entre engajamento e independência. $\mathrm{Na}$ ambição de pertencer a uma sociedade em movimento, dos que querem compreender e também transformar o mundo, como diz o citado editorial de Ramonet de janeiro de 2005 invocando a máxima marxista, tais intelectuais muitas vezes privilegiam o engajamento a priori à causa palestina, às custas de críticas e eventuais questionamentos que, se não puderem ser respondidos, deveriam no mínimo ser lançados à luz. 
No magazine, pululam discussões sensíveis sobreo papel dos intelectuais diante de disputas assimétricas (Ocidente versus Oriente, Israel versus Palestina), entre o engajamento (tomar partido, militar por uma causa) e a independência (lançar críticas e especialmente autocríticas ao que se faz em prol de uma causa, ainda que legítima).

Para Le Monde Diplomatique, resistir é necessário, conforme evidencia o primeiro editorial destacado de Ramonet, de maio de 2004. Mas as condições de tal resistência são imprecisas, como procurei destacar nestas páginas, por exemplo, nas aspas atribuídas ao termo "resistência" por Usher. Em outras palavras, resistir é preciso, mas a resistência não é precisa.

\section{Referências}

ANTES, Peter. O islã e a política. São Paulo: Paulinas, 2003.

BALIBAR, Etienne. Universalité de la cause palestinienne. Le Monde Diplomatique, Paris, maio 2004. p. 26-27.

BARBOSA, Marialva C. Manipulação midiática ou a dimensão declaratória da memória?

E-Compós, Brasília, v. 20, n. 2, p.1-17, maio/ ago. 2017.

. História cultural da imprensa: Brasil, 1900-2000. Rio de Janeiro: Mauad X, 2007.

. História cultural da imprensa: Brasil, 1800-1900. Rio de Janeiro: Mauad X, 2010.
CHALIAND, Gérard. Quand la resistánces' organise. Manière de Voir, Le Monde

Diplomatique, Paris, fev./mar. 2018. p.15-19.

DEMANT, Peter. 0 mundo muçulmano. 3. ed. São Paulo: Contexto, 2015.

GRESH, Alain. Les colonies ou la paix.

Manière de Voir, Le Monde Diplomatique,

Paris, fev. /mar.2018. p. 31-33.

. La Palestine, toujours recommencée.

Manière de Voir, Le Monde Diplomatique,

Paris, fev./mar. 2018. p. 94-97.

HARVEY, Nicolas. Le Monde diplomatique: un concept éditorial hybride au confluent $d u$ journalisme, de l'université et du militantisme. 2011. 386 f. Tese (Doutorado em Ciência Política)-Université de Rennes I, Rennes, 2011.

HOBSBAWM, Eric. Sobre história. Tradução Cid Knipel Moreira. 2. ed. São Paulo: Companhia das Letras, 1998.

IANNI, Octavio. Enigmas da modernidademundo. Rio de Janeiro: Civilização

Brasileira, 2000.

JUDT, Tony. Passado imperfeito: um olhar crítico sobre a intelectualidade francesa no pós-guerra. Tradução Luciana Nogueira. Rio de Janeiro: Nova Fronteira, 2007. .

KOSELLECK, Reinhart. Futuro passado: contribuição à semântica dos tempos históricos. Tradução Wilma Maas e Carlos Almeida. Rio de Janeiro: Contraponto/Ed. PUC-Rio, 2006.

LUCA, Tânia Regina de. Fontes impressas: história dos, nos e por meio dos periódicos. In: PINSKY, Carla Bassanezi (Org.). Fontes históricas. 3. ed. São Paulo: Contexto, 2014. p. 111-153. 
MEILHAC, Samuel Ghiles. Le Monde Diplomatique et Israël (1954-2005). Paris: Éditions Le Manuscrit, 2006. (Edição do Kindle).

MENEZES, Ulpiano T. Bezerra de. A história, cativa da memória? Revista do Instituto de Estudos Brasileiros, São Paulo, n. 34, p. 9-24, 1992.

PROST, Antoine. Doze lições sobre a história. Tradução Guilherme João de Freitas Teixeira. Belo Horizonte: Autêntica Editora, 2017.

RAMONET, Ignacio. La question palestinienne. Le Monde Diplomatique, Paris, dez. 1994. p. 1. . Oùva Israël? Le Monde Diplomatique, Paris, ago. 1998. p.1.

. Résistances. Le Monde Diplomatique, Paris, maio 2004. p. 1.

. Médias en crise. Le Monde

Diplomatique, Paris, jan. 2005, p. 26-27

ROUSSO, Henry. A última catástrofe: a história, o presente, o contemporâneo. Tradução Fernando Coelho e Fabrício Coelho. Rio de Janeiro: Editora FGV, 2016

SAID, Edward. Orientalismo: o Oriente como invenção do Ocidente. Tradução Rosa Eichenberg. São Paulo: Companhia das Letras, 2007.

. Comment conjurer le risqued'une perpétuelle soumission à l' Etatd' Israël. Le Monde Diplomatique, Paris, nov. 1993. p. 4-5. . Victimes consentantes. Le Monde Diplomatique, Paris, nov. 1994. p. 13. . Israël-Palestine, une troisième voie. Le Monde Diplomatique, Paris, ago. 1998. p. 9.
À Oslo, une redditionin conséquente. Manière de Voir, Le Monde Diplomatique, Paris, fev./ mar. 2018. p. 23-26.

SAYURI, Juliana. Paris - Buenos Aires. São Paulo: Alameda, 2018.

SIRINELLI, Jean-François. Os intelectuais. In. RÉMOND, René (Org.). Por uma história política. Tradução Dora Rocha. Rio de Janeiro: UFRJ/FGV, 1996. p. 231-269.

THOMPSON, John. A mídia e a modernidade. Tradução Wagner de Oliveira Brandão. 11. ed. Petrópolis: Vozes, 2009.

USHER, Graham. Impasse stratégique pour la résistance palestinienne. Le Monde Diplomatique, Paris, set. 2003. p. 12-13. Mise aupas de l'Autorité Palestinienne. Manière de Voir, Le Monde Diplomatique, Paris, fev./mar. 2018. p. 43-46

WEIL, Benjamin. Pas si diplomatique que ça: Le Monde Diplomatique et leconflitisraéloarabe de 2000 à 2006: une tentative d'analyse et d'interprétation. 2006. 146 f. Dissertação (Mestrado em Sociologia Política)-Université Paris I - Sorbonne, Paris, 2006. 


\section{Historical deadlocks: The Israeli- Palestinian conflict according to Le Monde Diplomatique's perspective}

\section{Abstract}

This article analyzes different dimensions of Le Monde Diplomatique's coverage of the IsraeliPalestinian conflict. Founded in the 1950 s in France as a diplomatic supplement to the daily Le Monde, the journal gradually reoriented its journalistic treatment of Israel (initially presented as a close ally) and consolidated itself as a key element of the French moviement in solidarity to the Palestinian people. This paper revisits these editorial changes and later discusses the memory dimension of the conflict as from the publication of old articles, written especially in the context of the Second Intifada (2000-2006) and reprinted to compose a 2018 dossier dedicated to Palestine.

\section{Keywords}

Le Monde Diplomatique. Intellectuals. Islam. Politics.
Impasses históricos: El conflito israelí-palestino según la perspectiva de Le Monde Diplomatique

\section{Resumen}

Este artículo analiza diferentes dimensiones de la cobertura de Le Monde Diplomatique acerca del conflicto israelí-palestino. Fundado en la década de 1950 en Francia como suplemento diplomático del diario Le Monde, el periódico gradualmente cambió su tratamiento periodístico a Israel (inicialmente presentado como un aliado cercano) y se consolidó como un elemento clave del movimiento francés de solidaridad al pueblo palestino. Este trabajo revisa estos cambios editoriales y luego analiza la dimensión de la memoria del conflicto a partir de la publicación de artículos antiguos, escritos especialmente en el contexto de la Segunda Intifada (2000-2006) y reimpresos para componer un dossier de 2018 dedicado a Palestina.

\section{Palabras clave}

Le Monde Diplomatique. Intelectuales. Islam. Política.

\section{Juliana Sayuri Ogassawara}

Doutora em História Social pela Universidade de São Paulo - USP. Pós-doutora em História pelo Programa de Pós-Graduação em História da Universidade Federal de Santa Catarina - UFSC, Florianópolis, Santa Catarina, Brasil. | E-mail: julianasayuri.o@gmail.com ORCID: https://orcid.org/0000-0001-6186-5313 